\title{
Diverse expression of selected cytokines and proteinases in synovial fluid obtained from osteoarthritic and healthy human knee joints
}

\author{
Martin Sauerschnig ${ }^{1,2^{*}}$, Josef Stolberg-Stolberg ${ }^{1}$, Anne Schulze², Gian Max Salzmann ${ }^{3}$, Carsten Perka ${ }^{2}$ \\ and Christian Jiri Dynybil ${ }^{2}$
}

\begin{abstract}
Background: Osteoarthritis $(\mathrm{OA})$ is defined by signs and symptoms of inflammation within the affected joint. The aim of this study is to determine the mRNA expression levels of selected cytokines and matrix-metalloproteinases of cells found in synovial fluid (SF) obtained from osteoarthritic knee joints compared to healthy controls.

Methods: SF was obtained from 40 patients undergoing total knee arthroplasty due to evident OA and from 10 healthy controls. Expression of TNF- $a, I L-1 \beta, M M P-1$ and MMP-3 was assayed among both groups by performing qPCR. Patients were configured concerning age, gender and BMI.

Results: IL-1 $\beta, M M P-1$ and MMP-3 showed significantly higher expression among the OA group compared to control $(P<0.001)$. Strong correlation appeared between expression of MMP-1 and MMP-3 among OA patients $(r=0.856)$; no correlation was found between age, gender or BMI and cytokine/proteinase expression. Expression of IL-1 $\beta$, MMP-1 and MMP-3 within SF was elevated in OA-patients.

Conclusion: Consequently, cells within SF expressing cytokines and proteinases may play a relevant role in the progression of joint destruction. Considering the fact that SF in an OA joint comprises abnormal amounts of detrimental bioactive proteins, temporary clearance, dilution or suppression/modulation by means of lavage or disease-modifying medication may be promising to constitute interim relief or even postpone disease progression due to decreased inflammatory and/or degrading activity within the articular environment.
\end{abstract}

Keywords: Cytokines, Proteinases, Osteoarthritis, Cartilage, Synovial fluid, Biomarkers

\section{Background}

Osteoarthritis $(\mathrm{OA})$ is characterized by slowly progressing destruction of the articular cartilage as well as an inflammatory reaction within the realms of the affected joint [1]. OA represents the most common joint disorder in the world and results in pain, deformity and gradual loss of joint function [1-3]. The origin includes mechanical injury, genetic factors and aging [4]. Disease progression is characterized by formation of osteophytes, subchondral bone cysts, increased thickness of the subchondral bone

\footnotetext{
* Correspondence: sauerschnig@gmail.com

'Department of Trauma Surgery, Klinikum rechts der Isar, Technische

Universitaet Muenchen, Munich, Germany

${ }^{2}$ Centrum für Muskuloskeletale Chirurgie, Charité-Universitätsmedizin Berlin,

Berlin, Germany

Full list of author information is available at the end of the article
}

plate and loss of articular cartilage [5]. The exact etiology of $\mathrm{OA}$, however, is not fully understood.

Synovial inflammation is commonly found in early stage $\mathrm{OA}$ and is characterized by joint swelling, redness, heat and pain [6,7]. The synovium is infiltrated by an increased number of synovial lining cells and immune cells such as macrophages, mast cells, T- and B-lymphocytes and plasma cells. Activated synovial cells, immune cells and chondrocytes produce large quantities of matrix metalloproteinases (MMPs) -1, -3, -9, -13 and ADAMTS, a disintegrin and metalloproteinase with thrombospondin motifs [8]. These proteolytic enzymes eventually degrade extracellular matrix macromolecules and cause a loss of cartilage integrity and biomechanical strength [9-11].

Proinflammatory cytokines act as soluble mediators and favor catabolic activities in articular cartilage $[12,13]$. 
Cytokine production is associated with certain immune cells while their specific origin in OA, however, is still unclear [14]. The proinflammatory cytokines IL-1 $\beta$ and TNF- $\alpha$ are found in elevated concentration in synovial fluid (SF) and joint tissue of OA patients. Both activate the JNK, p38 MAPK and NF- $\mathrm{BB}$ signaling pathways in chondrocytes $[15,16]$. They are capable of suppressing proteoglycan, collagen II and aggrecan expression while stimulating MMP expression and the production of further catabolic cytokines such as IL-6, IL-8, MCP-1 and CCL-5 [17].

$\mathrm{OA}$ is no longer understood as a disease merely caused by wear and tear but rather as an inflammatory process [18]. Definition of baseline cytokine and proteinase levels and their mRNA concentration in SF of healthy and OA patients is crucial to evaluate the potential for diagnosing early OA using cytokines as biomarkers [19]. The objective of this study was to elucidate whether the cells in the SF are producing the detrimental proteins mentioned above. Thus, we aimed to quantify mRNA expression patterns of the main inflammatory mediators IL- $1 \beta$ and TNF- $\alpha$ and degradative enzymes MMP-1 and MMP-3 within synovial fluid of OA patients compared to healthy controls. Such information would further define the role of the mentioned cytokines and proteases within the complex cascades of incidental/progressive $\mathrm{OA}$ and could strengthen their potential as biomarkers and/or novel therapeutic targets.

\section{Methods}

\section{Patients and donors}

Patient and donor characteristics are presented in Table 1. A total of 40 patients (18 females, 22 males) with clinically as well as radiographically-evident OA were included and SF was obtained prior to total knee arthroplasty (TKA). Furthermore, SF was obtained from a total of

Table 1 Osteoarthritis (OA) patient and control characteristics

\begin{tabular}{llll}
\hline & OA patients & Control (donors) & Total \\
\hline Gender & 22 & 6 & 28 \\
Male & 18 & 4 & 22 \\
Female & 40 & 10 & 50 \\
Total & & & \\
Age & $67.88 \pm 10.56$ & $51.4 \pm 6.36$ & $64.58 \pm 11.86$ \\
Mean & 39 to 99 & 42 to 62 & 39 to 99 \\
Range & & & $28.48 \pm 5.47$ \\
Body Mass Index & $29.28 \pm 5.77$ & $25.26 \pm 1.93$ & 21.1 to 44.2 \\
Mean & 21.1 to 44.2 & 22.2 to 28.3 & \\
Range &
\end{tabular}

Gender (male/female), age and body mass index (BMI) at the time of examination among OA patients and controls, mean \pm SD. Significance provided within results section.
10 controls/donors ( 4 females, 6 males) with no history of joint surgery or any cartilage/OA-related disease, within 4 hours after death due to insult or atraumatic intracranial bleeding. SF harvesting among patients as well as controls was performed utilizing a sterile syringe with the needle injected into the knee joint using a standardized anterolateral portal, strictly avoiding hemarthrosis. Single incision arthrotomy allowed then for direct visualization of the knee joint and cartilage evaluation was performed by an experienced orthopedic surgeon in order to exclude the presence of OA.

The study was performed in accordance with the Declaration of Helsinki. Informed consent from each patient as well as approval from the local ethics committee was obtained prior to investigation (Ethics commission, Charité, Berlin, EA1/083/09).

\section{RNA extraction}

After centrifugation of SF from OA patients and controls directly after harvest, the cell-pellet was disrupted in RA-1 lysis buffer (Macherey-Nagel, Düren, Germany) and stored at $-80^{\circ} \mathrm{C}$ until further analysis. Total RNA was then isolated from the cell-pellet yielded using the NucleoSpin RNA II $^{\odot}$ kit (Macherey-Nagel, Düren, Germany) according to the manufacturer's protocol.

\section{Reverse transcription}

A volume of $8 \mu \mathrm{l}$ mRNA template, $1 \mu \mathrm{l} 10 \mathrm{mM}$ Deoxynucleotide-Mix (dNTP-Mix, Invitrogen Life Technologies, Paisley, UK) and $1 \mu \mathrm{l}$ random primer (Invitrogen Life Technologies, Paisley, UK) was incubated for 5 minutes at $65^{\circ} \mathrm{C}$ in a thermocycler (Eppendorf, Hamburg, Germany) and then cooled down to $4^{\circ} \mathrm{C}$. A total of $9.5 \mu$ reaction mix consisting of $4 \mu \mathrm{l}$ reaction buffer (M-MLV RT 5x Reaktionspuffer, Promega GmbH, Mannheim, Deutschland), $1 \mu \mathrm{l}$ RNase inhibitor (RNase Inhibitor $40 \mathrm{U} / \mu \mathrm{l}$, Promega $\mathrm{GmbH}$, Mannheim, Deutschland) and $4.5 \mu \mathrm{l} \mathrm{H}_{2} \mathrm{O}$ were added and incubated at $42^{\circ} \mathrm{C}$ for 2 minutes. After adding $1 \mu \mathrm{l}$ of reverse transcriptase (M-MLV RT(H-) $200 \mathrm{U} / \mu \mathrm{l}$, Promega GmbH, Mannheim, Deutschland), an incubation period of 50 minutes at $42^{\circ} \mathrm{C}$ was followed by 15 minutes at $70^{\circ} \mathrm{C}$, producing the cDNA to be further analyzed via qPCR. After cooling to $4^{\circ} \mathrm{C}$, residual RNA was eliminated using $1 \mu \mathrm{l}$ of RNase (RNse $\mathrm{H} 250 \mathrm{U} / \mu \mathrm{l}$, Promega $\mathrm{GmbH}$, Mannheim, Deutschland) for 20 minutes at $37^{\circ} \mathrm{C}$.

\section{Quantitative polymerase chain reaction (qRT-PCR)}

Expression profiles were assessed via qRT-PCR on an iCycler detection system (Bio-Rad, Munich, Germany) using SYBR Green (Applied Biosystems, Foster City, CA, USA) as a fluorescent reporter. Primers were designed by TIB MOLBIOL (Syntheselabor GmbH, Berlin, Germany) and tested with the Basic Local Alignment Search Tool 
(BLAST). The human primer sequences used were as follows:

IL-13: 5' -CAGGGACAGGATATGGAGCAA-3' (forward)

5' -GCAGACTCAAATTCCAGCTTGTTA-3' (reverse)

TNF- $\alpha$ : 5'-CTTCTCCTTCCTGATCGTGGC-3' (forward)

5'-GGGTTTGCTACAACATGGGC-3' (reverse)

MMP-1: 5' -CCGGTTTTTCAAAGGGAATAAGTA-3' (forward)

5' -CGATATGCTTCACAGTTCTAGGGAA-3' (reverse)

MMP-3: 5' -AAACCCACCTTACATACAGGATTG-3' (forward)

5' -AAGTCTCCATGTTCTCTAACTGCA-3' (reverse)

GAPDH: 5' -CATGTTCGTCATGGGTGTG-3' (forward) 5' -GGCAGTGATGGCATGGACTG-3' (reverse)

The $25 \mu \mathrm{l}$ reaction-mix consisted of $1.0 \mu \mathrm{l}$ cDNA template, $12.5 \mu \mathrm{l}$ iQ Supermix (Bio-Rad, Munich, Germany), $0.5 \mu \mathrm{l}$ primer forward $(10 \mu \mathrm{M}), 0.5 \mu \mathrm{l}$ primer reverse $(10 \mu \mathrm{M}), 1.0 \mu \mathrm{l}$ SYBR-Green (Applied Biosystems, Foster City, CA, USA) and $9.5 \mu \mathrm{l}$ DNase-free water. iCycler settings involved activation of the polymerase reaction at $95^{\circ} \mathrm{C}$ (15 minutes), followed by 38 cycles of denaturation at $94^{\circ} \mathrm{C}$ (30 seconds), primer annealing at $59^{\circ} \mathrm{C}$ according to primer-specific requirements (40 seconds), elongation at $72^{\circ} \mathrm{C}$ (30 seconds) and fluorescence detection at $80^{\circ} \mathrm{C}$ (15 seconds). GAPDH was used as an internal control and all reactions were performed in triplicates followed by a specific melting curve analysis of each assay at $60^{\circ} \mathrm{C}$ to $95^{\circ} \mathrm{C}$ (30 seconds). Quantification of mRNA expression was assessed by the $2-\Delta \Delta C$ T method [20].

\section{Statistics}

The major determinant for outcome comparison was the expression level of the targeted cytokines and proteases according to the groups described above. Statistical analysis was performed using the software package SPSS version 17 (SPSS Inc., Chicago, IL, USA). All data were tested for normal distribution using the KolmogorovSmirnov test. The Mann-Whitney $U$-test was performed to assess differences in expression levels between groups corrected for cofounding variables (age, gender, BMI). Furthermore, Fisher's exact test was conducted to compare the frequency of detectable expressions between the groups. To control the family-wise error rate, the Bonferroni correction was applied. Unless stated otherwise, descriptive results were demonstrated as the mean \pm standard deviation (SD). Significance was set at $P<0.05$ for all tests.

\section{Results}

Participant characteristics

An overview of participant characteristics is given in Table 1. All patients showed clinically and radiographicallyevident knee OA. Controls showed no history of kneerelated pathologies and there was no intraarticular, no ligamentous and particularly no meniscal or cartilage pathology to be found in any control knee joint and the surrounding soft tissues were also without pathological findings. There was a significant overall group difference for age and BMI $(P<0.05)$ between groups.

\section{qPCR outcome}

IL-1 $\beta$, MMP- 1 and MMP-3 showed significantly higher expression levels among the OA group compared to the control $(P<0.001)$ while TNF- $\alpha$ expression differences never reached the level of significance $(P=0.077)$. Median and interquartile ranges (IQR: 25th to 75th percentile) are reported to depict differences in distribution of MMP-1, MMP-3, IL- $1 \beta$ and TNF- $\alpha$ between patients and donors/ controls and an overview is given in Table 2.

Frequency of detectable expression was $85.4 \%$ (OA) versus $0 \%$ (control) for MMP-1, 97.6\% (OA) versus $12.5 \%$ (control) for MMP-3, 95.1\% (OA) versus $25.0 \%$ (control) for IL-1 $\beta$ and $95.1 \%$ (OA) versus 37.5\% (control) for TNF- $\alpha$; the corresponding bar charts are given in Figure 1.

Furthermore, a strong correlation appeared between expression levels of MMP-1 and MMP-3 among OA patients $(r=0.856)$ while no such correlation was found between age, gender or BMI and the expression levels investigated.

\section{Discussion}

Inflammation plays a pivotal role in the pathogenesis of OA [4]. However, the cellular origin of inflammatory mediators and catabolic enzymes remains an area of speculation [14]. The aim of this study was to quantify and compare inflammatory and degradative markers on mRNA levels in cells floating in the SF of OA patients and healthy controls. The selection of TNF- $\alpha$, IL-1 $\beta$, MMP-1 and MMP-3 represents well-established inflammatory

Table 2 Expression levels in osteoarthritis (OA) patients and controls

\begin{tabular}{llllll}
\hline & & Median & \multicolumn{2}{c}{ Interquartile range } & P-value \\
\cline { 3 - 4 } & & $\mathbf{2 5}$ & $\mathbf{7 5}$ & \\
\hline MMP-1 & OA SF & 1.48 & 0.71 & 3.77 & $<0.001$ \\
& Donor SF & $<0.01$ & $<0.01$ & $<0.01$ & \\
MMP-3 & OA SF & 3.78 & 1.49 & 8.64 & $<0.001$ \\
& Donor SF & $<0.0$ & $<0.01$ & $<0.01$ & \\
IL-1 $\beta$ & OA SF & 1.41 & 0.72 & 4.09 & $<0.001$ \\
& Donor SF & $<0.01$ & $<0.01$ & 1.91 & \\
TNF-a & OA SF & 2.57 & 1.22 & 5.59 & 0.077 \\
& Donor SF & $<0.01$ & $<0.01$ & 6.27 & \\
\hline
\end{tabular}

Detectable expression levels of MMP-1, MMP-3, IL-1 $\beta$ and TNF- $\alpha$ within synovial fluid (SF) yield from affected patients (OA) and controls. Median and interquartile ranges (IQR: 25th to 75th percentile) are reported to depict differences in distribution. 


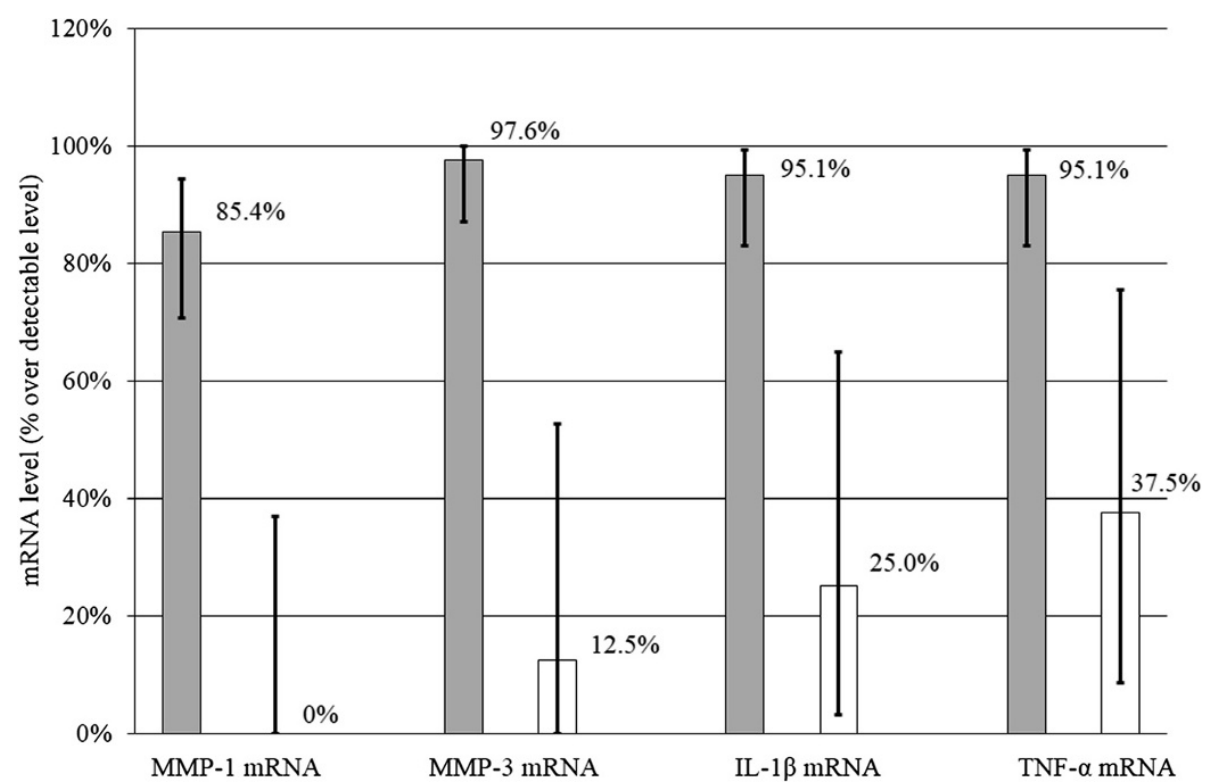

Figure 1 Frequency of detectable expressions of MMP-1, MMP-3, IL-1 $\beta$ and TNF- $\alpha$ within synovial fluid (SF) yield from affected patients $(\mathbf{O A})$ and controls. Corresponding bar charts are provided with $95 \%$ confidence intervals.

mediators and catabolic proteinases in OA $[15,18]$. The present study demonstrates that there is significantly more IL-1 $\beta$, MMP-1 and MMP-3 mRNA transcribed in SF cells of OA patients compared to healthy controls. The mean age of OA patients was slightly older compared to the donor group and older age could lead to a different onset of inflammatory response. Furthermore, there was a difference in mean BMI comparing OA patients and donors. Higher BMI causes higher joint load and one could imagine that this might interfere with the inflammatory response of the investigated joints. However, the immense differences between the two groups concerning frequencies of detectable expression of IL-1 $\beta$, MMP-1 and MMP-3 are not likely to be caused by the slight differences of patient age or BMI.

Increased levels of active IL- $1 \beta$ have already been found in SF of OA patients using ELISA [21-24]. Similar findings were made analyzing OA cartilage and synovial tissue using immunohistochemistry [25-27]. To our knowledge, this is the first study to analyze mRNA levels of IL-1 $\beta$ in SF cells of OA patients. Our data demonstrate a high inflammatory activity of SF cells via IL-1 $\beta$. However, it is not clear to what extent these cells act synergistically with cells within the synovial tissue and cartilage. Furthermore, IL-1ß's mRNA still has to be translated and IL-1ß's inflammatory potential is influenced by the presence of IL-1 $\beta$-converting enzyme, allocation of suitable receptors and other inflammatory processes. Our analysis of TNF- $\alpha$ mRNA concentration showed a wide range of results within the group of healthy controls and no significant difference to our OA group $(P=0.077)$.
Although TNF- $\alpha$ is accepted as one of the two most important inflammatory cytokines in OA today, conflicting reports are found in the literature. Early studies showed highly inconsistent levels of TNF- $\alpha$ expression in SF and synovial tissue of OA patients [24,28-30]. Furthermore, TNF- $\alpha$ levels in SF significantly correlate with clinical symptoms but not with radiographic findings of $\mathrm{OA}$ [31]. An answer to these contrary reports might be variations in number and susceptibility of chondrocyte TNF- $\alpha$ receptors, the presence of soluble TNF- $\alpha$ receptors and activity of TNF- $\alpha$-converting enzymes [24]. Alternatively, TNF- $\alpha$-expressing cells such as macrophages could mainly be localized in the synovial tissue [32].

IL-1 $\beta$ and TNF- $\alpha$ stimulate the production of cartilagedegrading enzymes [33,34]. As such, MMPs are of particular interest because they are considered as the major degradative enzymes in OA [11]. Augmented MMP levels were found in SF of OA patients and they are expressed by lining cells, neutrophils, macrophages and chondrocytes in the synovial tissue [35-38]. Moreover, our data indicate that a significant amount of MMPs is present within the synovial fluid. Again, it is not clear whether these MMPs are produced by cells in the surrounding tissues or by cells within SF. First and foremost, our data indicate that cells in the SF are significant contributors. Thus, this study gives valuable information about potential treatment options including replacement of SF. Arthroscopic joint irrigation has been reported to cause significant release of pain in early studies. Livesely and colleagues showed more pain relief after arthroscopic lavage and 
physiotherapy compared to physiotherapy alone [39]. In contrast, Moseley and co-workers showed no difference between arthroscopic irrigation and sham operations of OA knee joints, nor regarding pain or function [40]. However, patients in the latter study were predominantly male and younger than our cohort leading to the thought that only certain patients may profit from arthroscopic irrigation. Removing inflamed SF at an early OA stage might inhibit the start of the self-escalating inflammatory cycle whereas joint lavage of late-stage OA might have no or only mild/temporary effects.

Early diagnosis of OA presents another clinical challenge and is crucial for disease prevention. Conventional diagnostic tools such as radiographic and magnetic resonance imaging (MRI) showed limited sensitivity or are time-consuming and expensive [41]. Analysis of cartilage matrix molecules in body fluids is still only used as research tool and gene expression profiles in peripheral blood leukocytes showed ambivalent cytokine levels $[4,42]$. Alam and colleagues successfully showed in a canine animal model that biomarkers in SF such as tartrate-resistant acid phosphatase, MMP-2, and tissue inhibitor of MMP-2 can be used for diagnosis of early OA [43]. Another canine animal model by Garner and co-workers showed high sensitivity and specificity of IL-8 and monocyte chemoattractant protein-1 in SF to surgically-induced OA. Our data show that mRNA of IL-1 $\beta$, MMP-1 and - 3 in SF is a sensitive indicator for symptomatic OA [44]. Further research should evaluate whether these markers are also able to detect early or non-symptomatic OA and whether they can function as a prognostic tool.

\section{Conclusion}

Our findings show that SF of OA patients contains cells that actively promote inflammation via expression of proinflammatory mediators and joint-degrading enzymes. Although origin and type of cells still have to be investigated, this may offer an explanation as to why removal of OA SF can cause OA symptom relief. Furthermore, qPCR-based analysis of SF might offer a promising diagnostic tool and the data presented here lead to speculation towards potential pharmacologic OA intervention on a biological basis.

\footnotetext{
Abbreviations

OA: osteoarthritis; mRNA: messenger ribonucleic acid; SF: synovial fluid; TNF: tumor necrosis factor; IL: interleucin; MMP: matrix metalloproteinase; qPCR: quantitative polymerase chain reaction; BMl: body mass index; JNK: c-Jun N-terminal kinase; MAPK: Mitogen-activated protein kinase; NF-kB: nuclear factor 'kappa-light-chain-enhancer' of activated B-cells; MCP: monocyte chemotactic protein; CCL: chemokine ligand; dNTP: desoxy ribonukleotide triphosphate; RT: reverse transcriptase; cDNA: complementary desoxyribonucleic acid; BLAST: Basic Local Alignment Search Tool; GAPDH: glyceraldehyde 3-phosphate dehydrogenase; ELISA: enzyme linked immunosorbent assay; MRI: magnetic resonance imaging.
}

\section{Competing interests}

The authors declare that they have no competing interests.

\section{Authors' contributions}

All authors were involved in drafting the article or revising it critically for important intellectual content, and all authors approved the final version to be published. MS had full access to all the data in the study and takes responsibility for the integrity of the data and the accuracy of the data analysis.

\section{Author details}

${ }^{1}$ Department of Trauma Surgery, Klinikum rechts der Isar, Technische Universitaet Muenchen, Munich, Germany. ${ }^{2}$ Centrum für Muskuloskeletale Chirurgie, Charité-Universitätsmedizin Berlin, Berlin, Germany. ${ }^{3}$ Department of Orthopaedic and Trauma Surgery, Albert-Ludwigs University Freiburg, Freiburg im Breisgau, Germany.

Received: 28 October 2014 Accepted: 14 November 2014

Published online: 29 November 2014

\section{References}

1. Loeser RF, Goldring SR, Scanzello CR, Goldring MB: Osteoarthritis: a disease of the joint as an organ. Arthritis Rheum 2012, 64:1697-1707.

2. Arden N, Nevitt MC: Osteoarthritis: epidemiology. Best Pract Res Clin Rheumatol 2006, 20:3-25.

3. Zhang Y, Jordan JM: Epidemiology of osteoarthritis. Clin Geriatr Med 2010, 26:355-+

4. Goldring MB, Goldring SR: Osteoarthritis. J Cell Physiol 2007, 213:626-634.

5. Burr DB: Anatomy and physiology of the mineralized tissues: role in the pathogenesis of osteoarthrosis. Osteoarthritis Research Society 2004, 12(Suppl A):S20-S30.

6. Benito MJ, Veale DJ, Fitzgerald O, van den Berg WB, Bresnihan B: Synovial tissue inflammation in early and late osteoarthritis. Ann Rheum Dis 2005, 64:1263-1267.

7. Ayral X, Pickering EH, Woodworth TG, Mackillop N, Dougados M: Synovitis: a potential predictive factor of structural progression of medial tibiofemoral knee osteoarthritis - results of a 1 year longitudinal arthroscopic study in 422 patients. Osteoarthr Cartil 2005, 13:361-367.

8. Sellam J, Berenbaum F: The role of synovitis in pathophysiology and clinical symptoms of osteoarthritis. Nat Rev Rheumatol 2010, 6:625-635

9. Cawston TE, Wilson AJ: Understanding the role of tissue degrading enzymes and their inhibitors in development and disease. Best Pract Res Clin Rheumatol 2006, 20:983-1002.

10. Plaas A, Osborn B, Yoshihara Y, Bai Y, Bloom T, Nelson F, Mikecz K, Sandy JD: Aggrecanolysis in human osteoarthritis: confocal localization and biochemical characterization of ADAMTS5 - hyaluronan complexes in articular cartilages. Osteoarthr Cartil 2007, 15:719-734.

11. Rengel Y, Ospelt C, Gay S: Proteinases in the joint: clinical relevance of proteinases in joint destruction. Arthritis Res Ther 2007, 9(5):221.

12. Goldring SR, Goldring MB: The role of cytokines in cartilage matrix degeneration in osteoarthritis. Clin Orthop Relat Res 2004, (427 Suppl):S27-S36

13. Goldring MB, Berenbaum F: The regulation of chondrocyte function by proinflammatory mediators - Prostaglandins and nitric oxide. Clin Orthop Relat Res 2004, (427 Suppl):S37-S46.

14. de Lange-Brokaar BJE, loan-Facsinay A, van Osch GJVM, Zuurmond AM, Schoones J, Toes REM, Huizinga TWJ, Kloppenburg M: Synovial inflammation, immune cells and their cytokines in osteoarthritis: a review. Osteoarthritis Cartilage 2012, 20:1484-1499.

15. Goldring MB, Otero M, Tsuchimochi K, ljiri K, Li Y: Defining the roles of inflammatory and anabolic cytokines in cartilage metabolism. Ann Rheum Dis 2008, 67:75-82.

16. Kobayashi M, Squires GR, Mousa A, Tanzer M, Zukor DJ, Antoniou J, Feige U, Poole AR: Role of interleukin-1 and tumor necrosis factor a in matrix degradation of human osteoarthritic cartilage. Arthritis Rheum 2005, 52:128-135.

17. Kapoor M, Martel-Pelletier J, Lajeunesse D, Pelletier J-P, Fahmi H: Role of proinflammatory cytokines in the pathophysiology of osteoarthritis. Nat Rev Rheumatol 2011, 7:33-42.

18. Pelletier JP, Martel-Pelletier J, Abramson SB: Osteoarthritis, an inflammatory disease - Potential implication for the selection of new therapeutic targets. Arthritis Rheum 2001, 44:1237-1247. 
19. Chu CR, Williams AA, Coyle CH, Bowers ME: Early diagnosis to enable early treatment of pre-osteoarthritis. Arthritis Res Ther 2012, 14:212-212.

20. Livak KJ, Schmittgen TD: Analysis of relative gene expression data using real-time quantitative PCR and the 2(T)(-Delta Delta C) method. Methods 2001, 25:402-408.

21. Kubota $\mathrm{E}$, Imamura $\mathrm{H}$, Kubota $\mathrm{T}$, Shibata T, Murakami K: Interleukin 1 beta and stromelysin (MMP3) activity of synovial fluid as possible markers of osteoarthritis in the temporomandibular joint. J Oral Maxillofac Surg 1997, 55:20-27.

22. Marks PH, Donaldson MLC: Inflammatory cytokine profiles associated with chondral damage in the anterior cruciate ligament-deficient knee. Arthroscopy 2005, 21:1342-1347.

23. Mannami K, Mitsuhashi T, Takeshita H, Okada K, Kuzuhara A, Yamashita F, Sakakida K: Concentration of interleukin- 1 beta in serum and synovial fluid in patients with rheumatoid arthritis and those with osteoarthritis. Nihon Seikeigeka Gakkai zasshi 1989, 63:1343-1352.

24. Westacott $\mathrm{Cl}$, Sharif M: Cytokines in osteoarthritis: mediators or markers of joint destruction? Semin Arthritis Rheum 1996, 25:254-272.

25. Tetlow LC, Adlam DJ, Woolley DE: Matrix metalloproteinase and proinflammatory cytokine production by chondrocytes of human osteoarthritic cartilage - Associations with degenerative changes. Arthritis Rheum 2001, 44:585-594.

26. Z-m S, Ling M, Liu M, Zhang Y-G: Expression of interleukin-1beta and tumor necrosis factor-alpha in the synovium and synovial fluid of patients with Kashin-Beck disease and osteoarthritis. Nan Fang Yi Ke Da Xue Xue Bao 2009, 29:5-8.

27. Aigner T, Soeder S, Haag J: II-1 beta and BMPS - Interactive players of cartilage matrix degradation and regeneration. Eur Cell Mater 2006, 12:49-56.

28. Di Giovine FS, Nuki G, Duff GW: Tumour necrosis factor in synovial exudates. Ann Rheum Dis 1988, 47:768-772

29. Hopkins SJ, Meager A: Cytokines in synovial fluid ii. The presence of tumor necrosis factor and interferon. Clin Exp Immunol 1988, 73:88-92.

30. Brennan FM, Chantry D, Jackson AM, Maini RN, Feldmann M: Cytokine production in culture by cells isolated from the synovial membrane. J Autoimmun 1989, 2(Suppl):177-186.

31. Orita S, Koshi T, Mitsuka T, Miyagi M, Inoue G, Arai G, Ishikawa T, Hanaoka E, Yamashita K, Yamashita M, Equchi Y, Toyone T, Takahashi K, Ohtori S: Associations between proinflammatory cytokines in the synovial fluid and radiographic grading and pain-related scores in 47 consecutive patients with osteoarthritis of the knee. BMC Musculoskelet Disord 2011, 12:144

32. Bondeson J, Wainwright SD, Lauder S, Amos N, Hughes CE: The role of synovial macrophages and macrophage-produced cytokines in driving aggrecanases, matrix metalloproteinases, and other destructive and inflammatory responses in osteoarthritis. Arthritis Res Ther 2006, 8(6):R187.

33. Milner JM, Cawston TE: Matrix metalloproteinase knockout studies and the potential use of matrix metalloproteinase inhibitors in the rheumatic diseases. Curr Drug Targets Inflamm Allergy 2005, 4:363-375

34. Aida $Y$, Maeno M, Suzuki N, Shiratsuchi $H$, Motohashi M, Matsumura $H$ : The effect of IL-1 beta on the expression of matrix metalloproteinases and tissue inhibitors of matrix metalloproteinases in human chondrocytes. Life Sci 2005, 77:3210-3221.

35. Lohmander LS, Hoerrner LA, Lark MW: Metalloproteinases, tissue inhibitor, and proteoglycan fragments in knee synovial fluid in human osteoarthritis. Arthritis Rheum 1993, 36:181-189.

36. Tchetverikov I, Lohmander LS, Verzijl N, Huizinga TWJ, Tekoppele JM, Hanemaaijer R, DeGroot J: MMP protein and activity levels in synovial fluid from patients with joint injury, inflammatory arthritis, and osteoarthritis. Ann Rheum Dis 2005, 64:694-698.

37. Meszaros E, Malemud CJ: Prospects for treating osteoarthritis: enzyme-protein interactions regulating matrix metalloproteinase activity. Ther Adv Chronic Dis 2012, 3:219-229.

38. Yoshihara Y, Nakamura H, Obata K, Yamada H, Hayakawa T, Fujikawa K, Okada Y: Matrix metalloproteinases and tissue inhibitors of metalloproteinases in synovial fluids from patients with rheumatoid arthritis or osteoarthritis. Ann Rheum Dis 2000, 59:455-461.

39. Livesley PJ, Doherty M, Needoff M, Moulton A: Arthroscopic lavage of osteoarthritic knees. J Bone Joint Surg Br Vol 1991, 73:922-926.

40. Moseley JB, O'Malley K, Petersen NJ, Menke TJ, Brody BA, Kuykendall DH, Hollingsworth JC, Ashton CM, Wray NP: A controlled trial of arthroscopic surgery for osteoarthritis of the knee. N Engl J Med 2002, 347:81-88.
41. Pelletier J-P, Martel-Pelletier J: Imaging in osteoarthritis trials: useful or just expensive? Nat Clin Pract Rheum 2009, 5:76-77.

42. Attur M, Belitskaya-Lévy I, Oh C, Krasnokutsky S, Greenberg J, Samuels J, Smiles S, Lee S, Patel J, Al-Mussawir H, McDaniel G, Kraus VB, Abramson SB: Increased interleukin-1 $\beta$ gene expression in peripheral blood leukocytes is associated with increased pain and predicts risk for progression of symptomatic knee osteoarthritis. Arthritis Rheum 2011, 63:1908-1917.

43. Alam MR, Ji JR, Kim MS, Kim NS: Biomarkers for identifying the early phases of osteoarthritis secondary to medial patellar luxation in dogs. J Vet Sci 2011, 12:273-280.

44. Garner BC, Stoker AM, Kuroki K, Evans R, Cook CR, Cook JL: Using animal models in osteoarthritis biomarker research. J Knee Surg 2011, 24:251-264.

doi:10.1186/s40001-014-0065-5

Cite this article as: Sauerschnig et al:: Diverse expression of selected cytokines and proteinases in synovial fluid obtained from osteoarthritic and healthy human knee joints. European Journal of Medical Research 2014 19:65.

\section{Submit your next manuscript to BioMed Central and take full advantage of:}

- Convenient online submission

- Thorough peer review

- No space constraints or color figure charges

- Immediate publication on acceptance

- Inclusion in PubMed, CAS, Scopus and Google Scholar

- Research which is freely available for redistribution 